\title{
Simulation of entrained flow gasification reactor with Multi Phase Particle in Cell (MP-PIC) approach
}

\author{
Ramesh Timsina Rajan K. Thapa Britt M. E. Moldestad Marianne S. Eikeland \\ Department of Process, Energy and Environmental Technology, University of South-Eastern Norway, Porsgrunn, \\ $\{$ ramesh.timsina, rajan.k.thapa, britt.moldestad, marianne.eikeland\}@usn.no
}

\begin{abstract}
Entrained flow gasification is a promising technology for conversion of biomass into valuable fuels and chemicals. Residues and byproduct formed during a gasification process possess a significant challenge prior to the production of synthetic fuel (biofuel). Present work focuses on the simulation of an entrained flow gasification reactor in Barracuda, which is based on the Computational Particle Fluid Dynamics (CPFD) modelling. The model is validated against experimental gas compositions reported in the literature. The model was used to study the flow behavior as well as the distribution of product gases and temperature inside the reactor. Simulations showed zones of high and lowtemperature regions suggesting different reactions zones such as a partial combustion zone near a fuel injector followed by a gasification zone. The flow behavior inside the reactor shows zones of recirculation, spreading and the fast flowing zone. Results from the product gas distributions inside a reactor supports the reason behind the zones with different temperature.
\end{abstract}

Keywords: $\quad$ entrained flow, biomass gasification, CPFD, MP-PIC approach

\section{Introduction}

World economy primarily depends upon the use of fuels, dominated by the use of fossil fuels compared to the use of renewable fuels. Fossil fuels has a share of $81 \%$ in the total energy consumption (Dudley, 2018). Due to the negative impact of the use of the fossil fuels, clean and efficient energy sources are getting prioritized in the energies and climate policies across the globe (Solorio and Jörgens, 2020). Biomass energy is a carbon-neutral fuel due to its sustainable life cycle. Besides this, low amounts of $\mathrm{N}_{2}$ and $\mathrm{S}$ in biomass generates low emissions of NOx and SOx. Biomass has been one of the economic and efficient energy sources for the humankind for many years. Biomass energy covers about $14 \%$ of the global energy demands and plays an important role in replacing the fossil fuel (Bandara et al., 2018). Biomass gasification is a key technology for the conversion of biomass into syngas, a mixture of $\mathrm{CO}$ and $\mathrm{H}_{2}$. The produced syngas can be used as a source for the production of bio fuels, valuable chemicals as well as for the heat and power generation.
Nearly 25\% of the global emission in 2016 were generated by transport sector, out of which air- and road transportation accounts for 86\% (Guo, 2020). Fossils fuels primarily drive the transport sector. Among the different alternatives, second generation biofuels via gasification and catalytic conversion is a promising technology. Integration of biofuels from biomass does not require major infrastructure modification, which makes it very relevant to conservative industries such as aviation and marine (Guo, 2020).

Due to the high content of volatile matters, thermal gasification often encounters technical challenges related to tar formation. This problem can be overcome by operating at high temperatures $\left(>1100^{\circ} \mathrm{C}\right)$, which promotes tar-reforming reactions (Llamas et al., 2020). Entrained flow (EF) biomass gasification reactors meet this requirements and typically operate at high temperatures $\left(1300-1500^{\circ} \mathrm{C}\right)$ and high pressure $(25-30$ bar) (Molino et al., 2016).

EF gasification reactors can operate both in a slagging and non-slagging mode. Slagging mode EF biomass gasifiers are more flexible due the ability to melt the ash formed during the operation. Also, the EF gasifiers have high carbon conversion efficiency as compared to the fluidized bed gasifiers (Weiland et al., 2013).

In addition, solid fuel particles have typically very short residence time (2-3 sec) (Qin, 2012). Therefore, smaller particles of typically around a few hundred microns are needed to achieve good heat transfer and mixing (Guo, 2020). Pre-treatment of biomass particles to achieve particle size of a few hundred microns of feedstocks requires a high amounts of energy. Also, the less reactive products, i.e. soot and char, formed during the devolatilization steps limits the complete conversion of fuel. Therefore, it is crucial to model EF reactors accurately to the increase the overall efficiency.

Figure 1 depicts the different processes occurring inside a gasifier. The main chemical reactions for the biomass gasification process are listed below (R1-R7). Heat is supplied to the reactor during the primary pyrolysis/devolatilization, which gives the volatiles and char. Volatiles consists of non-condensable gases such as $\mathrm{CO}, \mathrm{CO}_{2}, \mathrm{CH}_{4}, \mathrm{H}_{2}$ and condensable tar. 


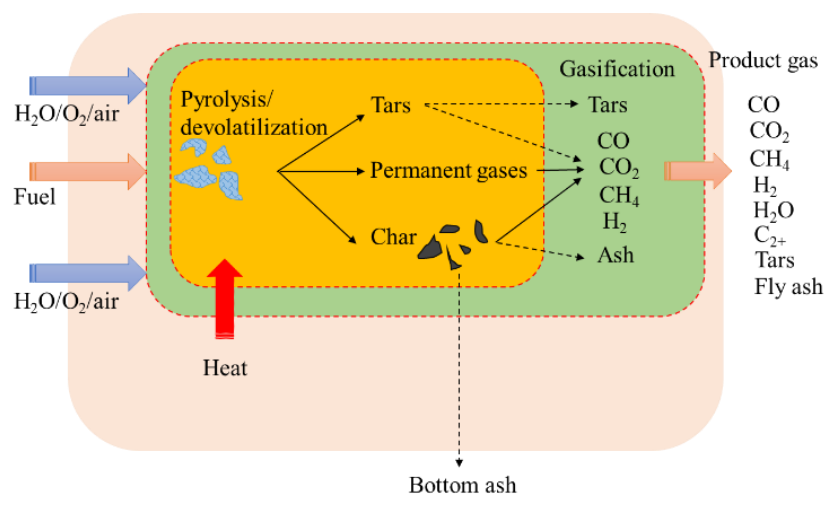

Figure 1. Process occurring in a gasifier: pyrolysis/devolatilization of fuel and gasification/reformation of the resulting gases and char

After initial decomposition, a variety of gas-solid and gas-gas reactions take place. Tars formed during the $\mathrm{EF}$ gasification cracks into light hydrocarbons such as $\mathrm{CH}_{4}$, $\mathrm{C}_{2+}$. Liu et al. have demonstrated that the reaction rate of char gasification is relatively high at a temperature range of 1273-1673K (Liu et al., 2006).

The hydrodynamics and the reactions are quite complex, which limits the optimization of a gasifier performance. It is difficult to study the hydrodynamics and reactions from the experimental tests. Simulation using computational fluid dynamics is becoming an important tool to study these parameters. During this study, a CPFD model is developed for the Pressurized Entrained Flow Biomass Gasification plant (PEBG) operated by Weiland et al. (2013).

\subsection{Previous works}

Wu et al. (2010) have studied EF coal slurry gasifiers. A three-dimensional numerical model based on the probability density function was developed and the simulation results agree well with the industrial data. Chen et al. (2012) have developed a numerical methods for the prediction of the coal gasification in an $\mathrm{EF}$ gasifier. The model particularly focused on the influence of the injection pattern and provide an accurate prediction for syngas formation. Abani and Ghoniem (2013) have developed a model for coal-fed EF gasifiers using large-eddy simulations and Reynolds-averaged Navier Stokes models. The model shows that the unsteady mixing is critical for the estimation of the product gas and carbon conversion. Kumar and Ghoniem (2013) have developed a multiscale model for EF gasifiers to investigate the effects of particle grinding size on carbon conversion. Fine grinding accelerated the char conversion under diffusion-control conditions, whereas there is not noticeable effects under kineticcontrol operation.

Due to the complexity of the EF gasification reaction and the limitation of the computational power, the above mentioned model were often simplified to two dimensional or semi three dimensional. Most of the simulations were based on the steady state simulations. There were also limited information about the particle temperatures, carbon content and locations for the discrete particles (Liang et al., 2020).

Liang et al. (2020) have developed a CPFD simulation model for an EF gasification reactor. The detailed particle information and residence time were studied. The rapid expansion from a tracer injector and fast reactions plays an important role in forming the particle distribution zone in the gasifiers.

Thus, further understanding of the reactor hydrodynamics and the transient behavior of the reactor is crucial. This paper will gives information about the transient behavior and the reactor hydrodynamics.

\section{Numerical model}

There are two distinct approaches in modelling of gassolid flows in an EF reactor: Eulerian-Eulerian (EE) and Eulerian-Lagrangian (EL) approach. EE modelling defines the gas and solid phases as continuous phases (interpenetrating continua). It lacks the detailed transient information of the two-phase interactions and does not accounts the particle size distribution of the slid phase. The EL approach models the solid phase as discrete elements and the motion of the individual particles is tracked by using Newton's law of motion. The fluid-particle, particle-particle, and particle-wall interaction as well as the particle size distribution is taken into account (Thapa et al., 2014). Thus, EL modelling requires a high computer power to calculate these interactions.

Multi-Phase Particle-In-Cell (MP-PIC) modelling was developed by considering a computational particle as a group of particles (called parcels) with the same size, density, residence time, velocity etc. Parcels are modelled in the discrete frame and the particle interaction are modelled in the Eulerian frame. Fluid particles are solved with an Eulerian set of equations. This reduces the computational costs for discrete modelling of the solid particles.

The main governing equations for CPFD simulations are based on MP-PIC approach and are described by Snider et al. (Snider, 2001; Snider and Banerjee, 2010).

Biomass undergoes devolatilization after the introduction into the reactor. Biomass is then decomposed into char particles and gases at the reactor temperature in the absence of oxygen. Equation 1 defines the global reaction for the devolatilization process (Authier and Lédé, 2013).

$$
\text { Wood } \stackrel{\text { heat }}{\longrightarrow} \mathrm{H}_{2}, \mathrm{CO}, \mathrm{CO}_{2}, \mathrm{CH}_{4}, \operatorname{chars}(\mathrm{s}), \text { tars }
$$

The minor elements such as sulphur and nitrogen are neglected and all the tar formed during the process converts into $\mathrm{CO}, \mathrm{CO}_{2}$ and $\mathrm{CH}_{4}$. The heavier hydrocarbons such as $\mathrm{C}_{2} \mathrm{H}_{2}, \mathrm{C}_{2} \mathrm{H}_{4}$ were neglected to 
make the model as simple as possible. The devolatilization rate is defined as (Wu et al., 2010):

$$
\frac{d m_{p}}{d t}=-A_{v} \mathrm{~T} \exp \left(\frac{E_{v}}{T}\right)\left(m_{p}-m_{c, a}\right)
$$

Where, $\mathrm{m}_{\mathrm{p}}$ is the particle mass and $\mathrm{m}_{\mathrm{c}, \mathrm{a}}$ is the mass of char and ash in the particle. The activation energy $\left(\mathrm{E}_{\mathrm{v}}\right)$ and the pre-exponential factor $\left(\mathrm{A}_{\mathrm{v}}\right)$ are $3945.15 \mathrm{~K}^{-1}$ and $2.1 \times 10^{5} \mathrm{~s}^{-1}$ respectively (Wu et al., 2010).

Char and ash are the main components of the particles after the devolatilization process. Char reacts with the gases present inside the reactor (heterogeneous reactions). The main reaction involving char gasification are as follows:

$$
\begin{aligned}
& 2 \mathrm{C}+\mathrm{O}_{2} \rightarrow 2 \mathrm{CO} \\
& \mathrm{C}+\mathrm{CO}_{2} \rightarrow 2 \mathrm{CO}
\end{aligned}
$$

The reaction rate for the heterogeneous reactions is determined by the intrinsic reaction rate and the diffusion rate. The expression for the intrinsic reaction rate and the diffusion rate can be found in the study of $\mathrm{Wu}$ et al. (2010). Further, char reactivity plays an important role in determining the reaction rate of these equations. The reactivity of char is given by:

$$
r_{m}=-\frac{1}{m_{c}} \frac{d m_{c}}{d t}=\frac{1}{\left(1-x_{c}\right)} \frac{d x_{c}}{d t}
$$

Where $m_{c}$ and $x_{c}$ are the mass of carbon contained in the sample and its conversion rate at time t (Gómez-Barea and Leckner, 2010).

A series of homogeneous reaction occurs inside the reactor. Five major global reaction were considered for this study.

$$
\begin{aligned}
& \mathrm{CO}+0.5 \mathrm{O}_{2} \rightarrow \mathrm{CO}_{2} \\
& \mathrm{H}_{2}+0.5 \mathrm{O}_{2} \rightarrow \mathrm{H}_{2} \mathrm{O} \\
& \mathrm{CH}_{4}+1.5 \mathrm{O}_{2} \rightarrow \mathrm{CO}+2 \mathrm{H}_{2} \mathrm{O} \\
& \mathrm{CO}+\mathrm{H}_{2} \mathrm{O} \rightarrow \mathrm{CO}_{2}+\mathrm{H}_{2} \\
& \mathrm{CH}_{4}+\mathrm{H}_{2} \mathrm{O} \rightarrow \mathrm{CO}+3 \mathrm{H}_{2}
\end{aligned}
$$

The reaction rates for these reactions are listed in Table 1.

Table 1. Reaction rate kinetics (Timsina et al., 2020)

\begin{tabular}{|lc|}
\hline Reactions & Reaction rate $\left(\right.$ mol.m $\left.^{-3} . \mathrm{s}^{-1}\right)$ \\
\hline $\mathrm{R} 1$ & $4.34 \times 10^{7} \mathrm{~m}_{\mathrm{s}} \mathrm{Texp}\left(\frac{-13590}{\mathrm{~T}}\right)\left[\mathrm{O}_{2}\right]$ \\
\hline $\mathrm{R} 2$ & $1.12 \times 10^{8} \mathrm{~m}_{\mathrm{s}} \mathrm{P}^{0.31} \theta_{\mathrm{f}} \exp \left(\frac{-29518}{\mathrm{~T}}\right)\left[\mathrm{CO}_{4}\right]$ \\
\hline R3 & $5.62 \times 10^{12} \exp \left(\frac{-16000}{\mathrm{~T}}\right)[\mathrm{CO}]\left[\mathrm{O}_{2}\right]^{0.5}$ \\
\hline R4 & $5.69 \times 10^{11} \exp \left(\frac{-17610}{\mathrm{~T}}\right)\left[\mathrm{H}_{2}\right]\left[\mathrm{O}_{2}\right]^{0.5}$ \\
\hline R5 & $5.0118 \times 10^{11} \exp \left(\frac{-24357}{\mathrm{~T}}\right)\left[\mathrm{CH}_{4}\right]^{0.7}\left[\mathrm{O}_{2}\right]^{0.8}$ \\
\hline
\end{tabular}

\begin{tabular}{|ll|}
\hline R6 & $7.68 \times 10^{10} \mathrm{Texp}\left(\frac{-36640}{\mathrm{~T}}\right)[\mathrm{CO}]^{0.5}\left[\mathrm{H}_{2} \mathrm{O}\right]$ \\
\hline R7 & $3 \times 10^{5} \exp \left(\frac{-15042}{\mathrm{~T}}\right)\left[\mathrm{CH}_{4}\right]\left[\mathrm{H}_{2} \mathrm{O}\right]$ \\
\hline
\end{tabular}

The temperature for the heterogeneous reactions were taken as a weighted average with $75 \%$ particle temperature and $25 \%$ gas temperature.

Barracuda includes the model for both gas-solids and gas-wall heat transfer as well as radiation model. It also has different built-in drag models (Software, 2016).

\section{Computational model}

The EF reactor simulated in this work is the same reactor constructed and operated by Weiland et al. (2013). The reactor diameter is $0.52 \mathrm{~m}$ and the height is $1.67 \mathrm{~m}$ as shown in Figure 2.

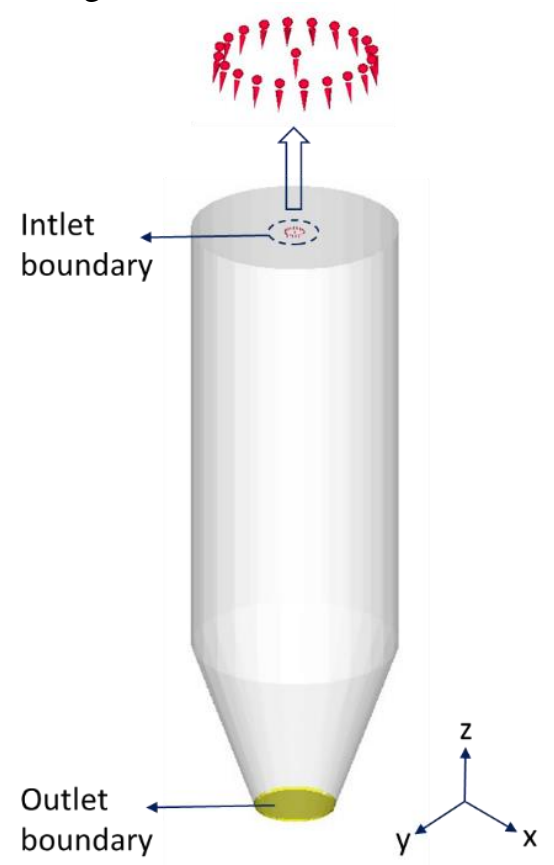

Figure 2. Schematic diagram of the CPFD model and its boundary conditions

A simulation model was developed in the Barracuda VR software. The reactor was modelled as an open cylinder with a conical shaped outlet at the bottom. The Wen-Yu-Ergun drag model was used for this work. A burner was modelled as an injector at the top center of the reactor. Other sets of injectors (20) were place concentrically outside of the fuel entrance burner. Oxygen required for gasification was supplied through these injector boundary parameters. The operating conditions of the reactor are shown in Table 2. Table 3 gives the properties of the biomass used during their study.

A total of 87300 real cells were generated using the inbuilt mesh generator available in Barracuda. In the CPFD simulations, the number of computational particles is controlled by a parameter called the number 
density (Software, 2016). Number density was set to 125000 to achieve a smoother and healthier particle feed for the system. This gives the particle to cell ratio of about 10:1.

Table 2. Experimental test conditions performed by Weiland et al. (2013)

\begin{tabular}{|ll|}
\hline Particle size, $\mu \mathrm{m}$ & 100 \\
\hline Fuel feeding rate, $\mathrm{kg} / \mathrm{h}$ & 40 \\
\hline Total $\mathrm{N}_{2}$ inlet, $\mathrm{kg} / \mathrm{h}$ & 14.4 \\
\hline $\mathrm{O}_{2}$ inlet, $\mathrm{kg} / \mathrm{h}$ & 26.6 \\
\hline $\mathrm{O}_{2}$ equivalence ratio & 0.44 \\
\hline System pressure, bar & 1.94 \\
\hline
\end{tabular}

Injection boundary conditions were used to define the inflow of fuel and gasifying agents along with nitrogen into the reactor. Accuracy of the injection boundary is not affected by the mesh sizes of the geometry. The angle of expansion of the injection boundary was set to $20^{\circ}$ but it is significantly dependent upon the gas behavior inside the reactor. A pressure boundary was defined at the bottom of the reactor to allow the outflow of the gas and the solid particles.

Table 3. Properties of the soft stem wood used by Weiland et al. (2013)

\begin{tabular}{|ll|}
\hline Proximate analysis (wt. \%, dry) & \\
\hline Fixed carbon & 15.1 \\
Volatile matter & 84.5 \\
Ash & 0.4 \\
\hline Ultimate analysis (wt. \%, dry) \\
\hline C \\
H & 50.90 \\
O & 6.30 \\
N & 42.4 \\
S & 0.10 \\
Cl & 0.006 \\
\hline
\end{tabular}

\section{Results}

The developed model was simulated for 50 seconds. The average gas composition were taken as the time average over final 20 seconds of simulations. The obtained results were compared with the results from an experiment performed by Weiland et al. (2013) ${ }^{1}$.

The average molar composition of the produced gas on nitrogen free dry basis is 0.457 of $\mathrm{CO}, 0.275$ of $\mathrm{H}_{2}$, 0.226 of $\mathrm{CO}_{2}$ and 0.038 of $\mathrm{CH}_{4}$. Table 4 shows that the simulation results agree well with the experimental results. The mole percentage of $\mathrm{CH}_{4}$ in the experiment also includes the mole percentage of $\mathrm{C}_{2} \mathrm{H}_{2}(0.3)$ and $\mathrm{C}_{2} \mathrm{H}_{4}(0.1)$.
Table 4. Comparison between the simulation and experimental results (mole percentage on nitrogen free dry basis)

\begin{tabular}{|l|llll|}
\hline \multirow{2}{*}{} & \multicolumn{4}{|c|}{ Product gas species } \\
\cline { 2 - 5 } & $\mathrm{CH}_{4}$ & $\mathrm{CO}$ & $\mathrm{CO}_{2}$ & $\mathrm{H}_{2}$ \\
\hline Simulation & 3.8 & 45.7 & 22.6 & 27.5 \\
\hline Experiment & 2.7 & 48.5 & 21.1 & 27.8 \\
\hline
\end{tabular}

As the EF gasification reactors operate at a high temperature, it was desired to monitor the reactor temperature. The gas temperature distribution inside the reactor is presented in Figure 3.

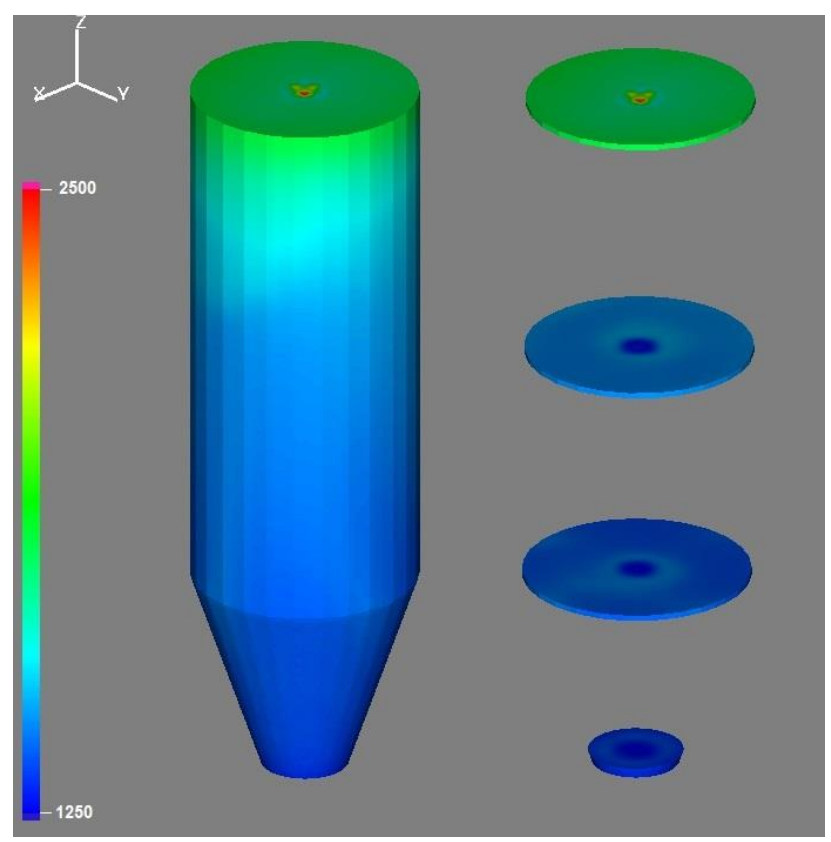

Figure 3. Gas temperature $(\mathrm{K})$ distribution inside the reactor

It can be seen from Figure 3 that the temperature around the fuel injector is comparatively higher than in the rest of the reactor. Often the reactor injector up to the burners are purged with nitrogen to avoid the burning of biomass before the burner (Weiland et al., 2013). The reactor temperature at different cross sections (right) shows that the temperature distribution becomes uniform with an increase in the reactor depth.

The product gas composition was monitored along the height of the reactor. Figure 4 shows the mole fractions of $\mathrm{CO}, \mathrm{H}_{2}$ and $\mathrm{CO}_{2}$ along the height of the reactor. There is a high concentration of $\mathrm{CO}$ and $\mathrm{H}_{2}$ along the center of the reactor. From the distribution of the $\mathrm{CO}$, it can be seen that there are dead spots at the top corner of the reactor. This gives rise to the uneven distribution of the gas components and the temperature inside the reactor. The gas distribution is similar along the radial direction except for in the top region (high temperature region as can be seen from Figure 3 ).

\footnotetext{
${ }^{1}$ Results are taken from the experiment on 14 February.
} 


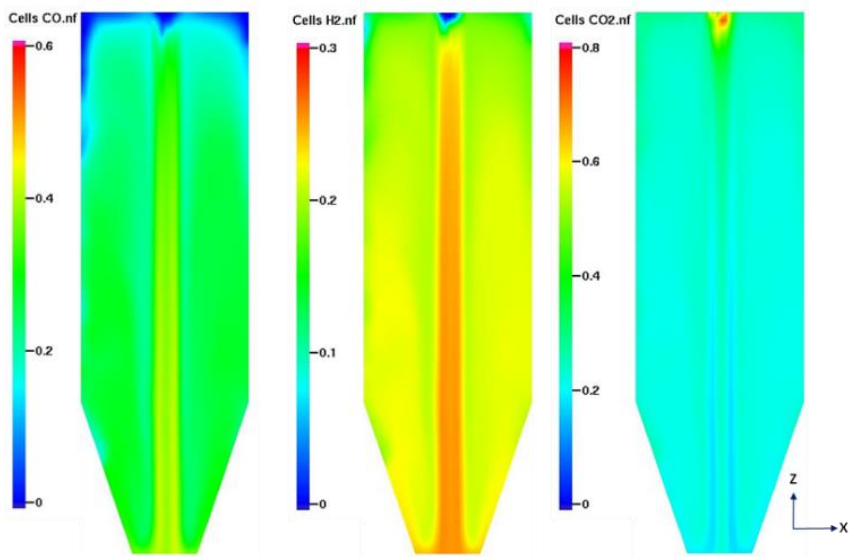

Figure 4. Gas composition along the reactor (mole fraction at $\mathrm{t}=30 \mathrm{sec}$ )

The high temperature close to the fuel burner (fuel injector) gives rise to high concentration of $\mathrm{CO}_{2}$ and low concentration of $\mathrm{CO}$ and $\mathrm{H}_{2}$. As the mixture of biomass and the pyrolysis gas move down, several chemical and physical transformation of the biomass occurs resulting in the product gas composition as shown in the Figure 4.
Therefore, it is important to know the fluid velocity and direction inside the reactor. Figure 5 shows the instantaneous fluid velocity distribution. It can be seen from the figure that recirculation of gas occurs near the wall of the reactor. The gas velocity in the central region gradually increases as it flows downward in the gasifier. The rapid gas expansion as well as recirculation is due to the expansion effects of the injection nozzles. Due to the jet velocity along the axial direction, expansion in radial direction is high compared to the axial direction. This is in agreement with the published result by Liang et al. (2020), where the reactor has three distinct flowing zones, i.e. the recirculation zone, the spreading zone and the fast flowing zone. The flow direction is random except in the middle of the reactor. This behavior has a great influence on the particle flow as well as the overall conversion efficiency of the process.

A summary of the results from the experiment can be obtained from the published article by Weiland et al. (2013). The article also compares the results from the different gasification technologies. A gasification process with higher concentration of $\mathrm{CH}_{4}$ in the product gas is more suitable for power generation as well as for Substitute Natural Gas (SNG) production.

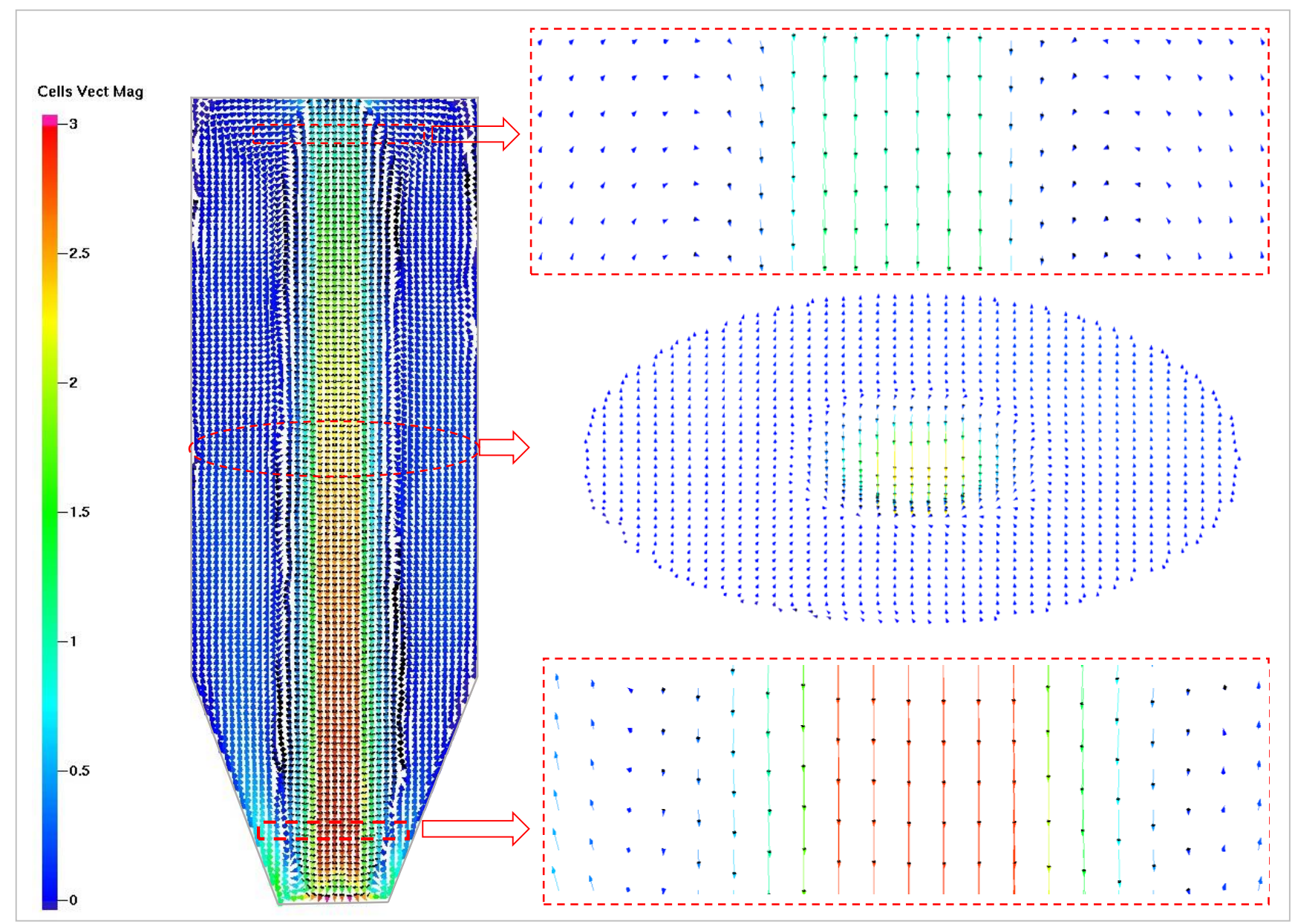

Figure 5. Gas speed distribution at $\mathrm{t}=30 \mathrm{sec}$. 
The $\mathrm{H}_{2} / \mathrm{CO}$ ratio is an important parameter for the conversion of syngas into synthetic fuels. The ratio of $\mathrm{H}_{2} / \mathrm{CO}$ will vary depending upon the synthesis route. For example, the low temperature Fischer-Tropsch synthesis (FT Synthesis) requires $\mathrm{H}_{2} / \mathrm{CO}$ ratio in the range of $1.7-2.15$ depending upon the catalyst, while the ratio is approximately 1.05 for FT synthesis at higher temperature (Weiland et al., 2013). Therefore, syngas requires shifting towards high $\mathrm{H}_{2}$ content prior to the fuel synthesis irrespective of the gasification technology.

Higher operating temperature for the EF reactor reduces the amounts of tar and heavier hydrocarbons in the product gas compared to the other gasification technologies. This potentially reduces the cost for the extensive syngas cleaning prior to fuel synthesis. However, the gasification pressure needs to be high enough to make the conversion process economically feasible. The convective and radiative losses from the reactor also plays an important role for the thermal efficiency of the plants. Dry biomass powder was gasified during the experiments in PEBG gasifier.

However, Brown et al. (1986) have shown that the premixing of the coal with steam or coal with moisture gave high concentration of $\mathrm{H}_{2}$, but lower $\mathrm{CO} /$ $\mathrm{CO}_{2}$ ratio decreases the carbon conversion. This could be due to the reduced gasification temperature.

Therefore, it is important to characterize (pros and cons) different alternatives before selecting a suitable conversion technology for the conversion of the biomass into biofuels via gasification. The difficulty of understanding the hydrodynamics as well as the reaction chemistry during an experiment can be studied by developing a simulation model. A CPFD model can give a detail insight of the reaction operating conditions, which in turn help a lot for the optimization and design of the EF reactor.

\section{Conclusion}

A CPFD simulation model was developed in Barracuda using the MP-PIC modelling approach. The model was used to simulate a pressurized entrained flow biomass gasification reactor operated by Weiland et al. (2013). The composition of the product gases obtained from the model agree well with the experimental results. The average molar composition of the produced gas on nitrogen free dry basis is 0.457 of $\mathrm{CO}, 0.275$ of $\mathrm{H}_{2}, 0.226$ of $\mathrm{CO}_{2}$ and 0.038 of $\mathrm{CH}_{4}$. An accurate prediction of the reactor performance is a challenging task, which is investigated in this study. A simple CFD model is presented in this work, which needs testing in different conditions and the authors believe that the model will be of use in the development and design of the entrained flow biomass reactor.

The gas expansion played a significant role for the particle speed and direction inside a reactor. Certain groups of particles in the center of the reactor has higher velocity and lower residence time. Other groups of the particles are recirculated giving a different flow direction and velocity. The $\mathrm{CO}_{2}$ concentration is highest and the $\mathrm{CO}$ and $\mathrm{H}_{2}$ concentration is lowest at the fuel injector.

Selection of suitable technology for the production of syngas prior to the synthetic fuel production depends upon different criteria such as biomass feed, desired syngas quality, capacity and costs. Entrained flow reactors are best suited for a feed with small particles at large capacity, at high temperatures and high pressures. Entrained flow reactors give cleaner syngas compared to fluidized and fixed bed reactors, which potentially reduces the cost for the extensive syngas cleaning prior to fuel synthesis.

\section{Acknowledgements}

The authors would like to thank the University of SouthEastern Norway (USN) for providing the Barracuda VR simulation tool.

\begin{tabular}{ll}
\multicolumn{2}{l}{ Abbreviations } \\
CPFD & Computational Particle Fluid Dynamics \\
EF & Entrained flow \\
EE & Eulerian-Eulerian \\
EL & Eulerian-Lagrangian \\
FT & Fischer-Tropsch synthesis \\
Synthesis & \\
MP-PIC & Multi-Phase Particle-In-Cell \\
PEBG & Pressurized Entrained Flow Biomass \\
SNG & Gasification plant \\
& Substitute Natural Gas
\end{tabular}

\section{References}

N. Abani and A. F. Ghoniem. Large eddy simulations of coal gasification in an entrained flow gasifier. Fuel 104: 664680, 2013. doi.org/10.1016/j.fuel.2012.06.006.

O. Authier and J. Lédé. The image furnace for studying thermal reactions involving solids. Application to wood pyrolysis and gasification, and vapours catalytic cracking. Fuel 107: 555-569, 2013. doi.org/10.1016/j.fuel.2013.01.041.

J. C. Bandara, B. ME. Moldestad and M. S. Eikeland. Analysing the effect of temperature for steam fluidized-bed gasification of biomass with MP-PIC simulation. International Journal of Energy and Environment 9(6): 529-542, 2018.

Blaine W. Brown, L. Douglas Smoot and Paul O. Hedman. Effect of coal type on entrained gasification. Fuel 65(5): 673-678. 1986. doi.org/10.1016/0016-2361(86)90363-7.

C-J. Chen, H. Chen-I., and W-H. Chen. Numerical investigation on performance of coal gasification under various injection patterns in an entrained flow gasifier. Applied energy 100: 218-228. 2012. doi.org/10.1016/j.apenergy.2012.05.013. 
B. Dudley. BP statistical review of world energy. BP Statistical Review, London, UK, accessed June 30 2020: 2018.

A. Gómez-Barea and B. Leckner. Modeling of biomass gasification in fluidized bed. Progress in Energy and Combustion Science 36(4): 444-509. 2010. doi.org/10.1016/j.pecs.2009.12.002.

N. Guo. Modelling of reacting multi-phase flow for biomass gasification. Doctoral theses at NTNU 1-224. 2020.

M. Kumar and A. F. Ghoniem. Application of a validated gasification model to determine the impact of coal particle grinding size on carbon conversion. Fuel 108: 565-577. 2013. doi.org/10.1016/j.fuel.2013.02.009.

Y. Liang, C.Y. Guo, X. Zhao, Q. Qin, Y. Cheng, and L. He. CPFD simulation on particle behaviour in an entrained-flow gasifier. Clean Energy 4(1): 75-84. 2020. doi.org/10.1093/ce/zkz032.

H. Liu, C. Luo, S. Kato, S. Uemiya, M. Kaneko andT. Kojima. Kinetics of $\mathrm{CO}_{2} / \mathrm{Char}$ gasification at elevated temperatures: Part I: Experimental results. Fuel Processing Technology 87(9): 775-781. 2006. doi.org/10.1016/j.fuproc.2006.02.006.

Á. D. G. Llamas, N. Guo, T. Li, R. Gebart, T. Løvås, and K. Umeki. Morphology and volume fraction of biomass particles in a jet flow during devolatilization. Fuel 278: 118241. 2020. doi.org/10.1016/j.fuel.2020.118241.

A. Molino, S. Chianese, and D. Musmarra. Biomass gasification technology: The state of the art overview. Journal of Energy Chemistry 25(1): 10-25. 2016. doi.org/10.1016/j.jechem.2015.11.005.

K. Qin, A. D. Jensen, P. A. Jensen and W. Lin. Entrained Flow Gasification of Biomass. Technical University of Denmark, Department of Chemical Engineering. 1-224. 2012.

D. M. Snider. An incompressible three-dimensional multiphase particle-in-cell model for dense particle flows. Journal of computational physics 170(2): 523-549. 2001. doi.org/10.1006/jcph.2001.6747.

D. M. Snider and S. Banerjee. Heterogeneous gas chemistry in the CPFD Eulerian-Lagrangian numerical scheme (ozone decomposition). Powder Technology 199(1): 100106. 2010. doi.org/10.1016/j.powtec.2009.04.023.

C. Software. Barracuda Virtual Reactor User Manual. CPFD Software LLC. Albuquerque. 2016

I. Solorio and H. Jörgens. Contested energy transition? Europeanization and authority turns in EU renewable energy policy. Journal of European Integration 42(1): 77 93. 2020. doi.org/10.1080/07036337.2019.1708342.

R. Thapa, C. Pfeifer and B. M. Halvorsen. Modeling of reaction kinetics in bubbling fluidized bed biomass gasification reactor. Int. J. Energy Environment 5: 35-44, 2014.

R. Timsina, R. K. Thapa, B. M. E. Moldestad and M. Eikeland. Experiments and computational particle fluid dynamics simulations of biomass gasification in an airblown fluidized bed gasifier. Int. J. of Energy Prod. \& Mgmt. 5(2): 102-114. 2020. doi.org/10.2495/EQ-V5-N2$\underline{102-114}$.
F. Weiland, H. Hedman, M. Marklund, H. Wiinikka, O. Öhrman, and R. Gebart. Pressurized oxygen blown entrained-flow gasification of wood powder. Energy \& Fuels 27(2): 932-941. 2013. doi.org/10.1021/ef301803s.

Y. Wu, J. Zhang, P. J. Smith, H. Zhang, C. Reid, J. Lv, and G. Yue. Three-dimensional simulation for an entrained flow coal slurry gasifier. Energy \& Fuels 24(2): 1156-1163. 2010. doi.org/10.1021/ef901085b. 